\title{
Author Index Volume 9 (2001)
}

The issue number is given in front of the page numbers.

Atluri, V., see Jajodia, S.

(3) $165-195$

Berezin, S., see Song, D.X.

$(1,2) \quad 47-74$

Besson, F., T. Jensen, D. Le Métayer and T. Thorn, Model checking security properties of control flow graphs

(3) $217-250$

Clarke, D., J.-E. Elien, C. Ellison, M. Fredette, A. Morcos and R.L. Rivest, Certificate chain discovery in SPKI/SDSI

(4) $285-322$

De Capitani di Vimercati, S., P. Lincoln, L. Ricciulli and P. Samarati, Global infrastructure protection system

(4) $251-283$

(4) $285-322$

Elien, J.-E., see Clarke, D.

Ellison, C., see Clarke, D.

(4) $285-322$

Fredette, M., see Clarke, D.

(4) $285-322$

Halpern, J.Y. and R. van der Meyden, A logic for SDSI's linked local name spaces

Hui, M.L. and G. Lowe, Fault-preserving simplifying transformations for security protocols

$(1,2) 105-142$

$(1,2) \quad 3-46$

Jajodia, S., V. Atluri, T.F. Keefe, C.D. McCollum and R. Mukkamala, Multilevel secure transaction processing

Jensen, T., see Besson, F.

(3) $165-195$

(3) $217-250$

Keefe, T.F., see Jajodia, S.

(3) $165-195$

Le Métayer, D., see Besson, F.

Lincoln, P., see De Capitani di Vimercati, S.

(3) $217-250$

Lincoln, P.D., see Wright, R.N.

Lowe, G., see Hui, M.L.

(4) $251-283$

(4) 323-338

$(1,2) \quad 3-46$

McCollum, C.D., see Jajodia, S.

(3) $165-195$

Meadows, C., A cost-based framework for analysis of denial of service in networks

$(1,2) 143-164$

Millen, J.K., see Wright, R.N.

Morcos, A., see Clarke, D.

(4) $323-338$

Mukkamala, R., see Jajodia, S.

(4) $285-322$

(3) $165-195$ 
Paulson, L.C., Relations between secrets: two formal analyses of the Yahalom protocol

(3) $197-216$

Perrig, A., see Song, D.X.

$(1,2) \quad 47-74$

Ricciulli, L., see De Capitani di Vimercati, S.

(4) $251-283$

Rivest, R.L., see Clarke, D.

Ryan, P.Y.A. and S.A. Schneider, Process algebra and non-interference

(4) $285-322$

$(1,2) \quad 75-103$

Samarati, P., see De Capitani di Vimercati, S.

Schneider, S.A., see Ryan, P.Y.A.

(4) $251-283$

Song, D.X., S. Berezin and A. Perrig, Athena: a novel approach to efficient automatic security protocol analysis

$(1,2) \quad 75-103$

$(1,2) \quad 47-74$

Thorn, T., see Besson, F.

(3) $217-250$

van der Meyden, R., see Halpern, J.Y.

$(1,2) 105-142$

Wright, R.N., P.D. Lincoln and J.K. Millen, Depender graphs: A method of fault-tolerant certificate distribution

(4) $323-338$ 